\title{
Case Study: A Measurement Program for Product Lines
}

Sholom Cohen, Software Engineering Institute Dave Zubrow, Software Engineering Institute Ed Dunn, Naval Undersea Warfare Center

May 2004

Product Line Practice Initiative

Unlimited distribution subject to the copyright.

Technical Note CMU/SEI-2004-TN-023 
The Software Engineering Institute is a federally funded research and development center sponsored by the U.S. Department of Defense.

Copyright 2004 by Carnegie Mellon University.

NO WARRANTY

THIS CARNEGIE MELLON UNIVERSITY AND SOFTWARE ENGINEERING INSTITUTE MATERIAL IS FURNISHED ON AN "AS-IS" BASIS. CARNEGIE MELLON UNIVERSITY MAKES NO WARRANTIES OF ANY KIND, EITHER EXPRESSED OR IMPLIED, AS TO ANY MATTER INCLUDING, BUT NOT LIMITED TO, WARRANTY OF FITNESS FOR PURPOSE OR MERCHANTABILITY, EXCLUSIVITY, OR RESULTS OBTAINED FROM USE OF THE MATERIAL. CARNEGIE MELLON UNIVERSITY DOES NOT MAKE ANY WARRANTY OF ANY KIND WITH RESPECT TO FREEDOM FROM PATENT, TRADEMARK, OR COPYRIGHT INFRINGEMENT.

Use of any trademarks in this report is not intended in any way to infringe on the rights of the trademark holder.

Internal use. Permission to reproduce this document and to prepare derivative works from this document for internal use is granted, provided the copyright and "No Warranty" statements are included with all reproductions and derivative works.

External use. Requests for permission to reproduce this document or prepare derivative works of this document for external and commercial use should be addressed to the SEI Licensing Agent.

This work was created in the performance of Federal Government Contract Number F19628-00-C-0003 with Carnegie Mellon University for the operation of the Software Engineering Institute, a federally funded research and development center. The Government of the United States has a royalty-free government-purpose license to use, duplicate, or disclose the work, in whole or in part and in any manner, and to have or permit others to do so, for government purposes pursuant to the copyright license under the clause at 252.227-7013.

For information about purchasing paper copies of SEI reports, please visit the publications portion of our Web site (http://www.sei.cmu.edu/publications/pubweb.html). 


\section{Contents}

Executive Summary ................................................................................... vii

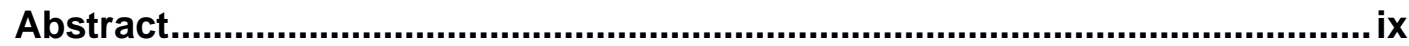

1 Introduction........................................................................................... 1

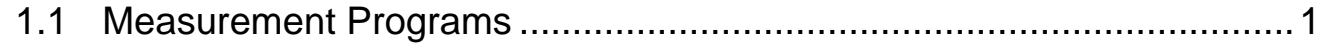

1.2 The NUWC Product Line Activity ............................................... 2

1.3 Report Organization and Related Work ........................................ 3

2 The Software Measurement Program at NUWC .................................... 5

2.1 Software Measurement Team .................................................. 5

2.2 Goals and Questions for a Measurement Program ........................... 6

2.3 Questions and Indicators ....................................................... 8

2.4 Data Elements and Sources ................................................... 10

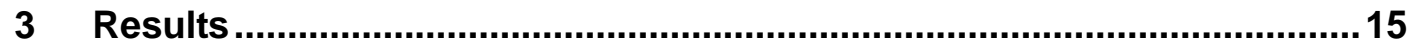

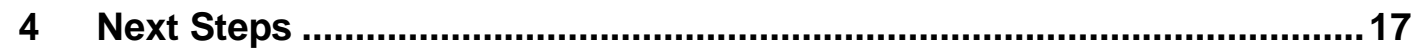

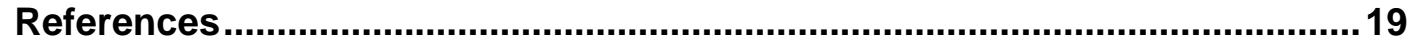




\section{List of Figures}

Figure 1: Goal-Driven Software Measurement .......................................... 2

Figure 2: $\quad$ Refinement of Overarching Goal into Subgoal $1 \ldots \ldots \ldots \ldots \ldots \ldots \ldots \ldots \ldots \ldots . \ldots \ldots$

Figure 3: Effort Indicator for Improving the Accuracy of Cost Estimation ............. 10 
CMU/SEI-2004-TN-023 


\section{List of Tables}

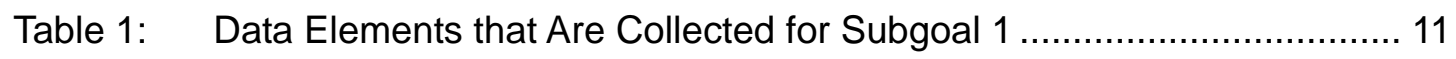

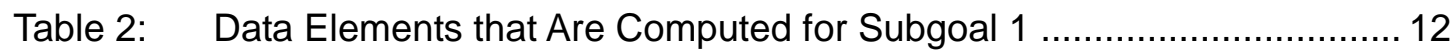

Table 3: $\quad$ Availability and Sources of Required Data Elements .......................... 13

Table 4: $\quad$ Initial Results from Data Collection ............................................ 16 


\section{Executive Summary}

A well-managed organization sets goals that address a long-term strategy. The organization defines objectives or subgoals that satisfy the strategy, creating a plan and applying resources to achieve the objectives. The organization uses data that track the state of the effort to determine whether the goals are being achieved as time passes (that is, whether the plan is working). By tracking and analyzing relevant measurable attributes of the effort's process and product as metrics, the organization's managers track progress toward achieving the goals. The managers can also detect issues that indicate when the effort has diverged from expectations. They can then revise the goals, plan, or resources to address these issues - or recalibrate everyone's expectations [Clements 02].

To guide decision making for the Naval Undersea Warfare Center (NUWC) Division Newport Ranges, Engineering, and Analysis Department's product line effort [Cohen 02], management has created a measurement program for its product line work. The Goal-Driven Measurement approach [Park 96] provided the basis for setting up the program, and NUWC established a software measurement team to develop and monitor the program. Data from the East Coast Shallow Water Test Range project served as the first trial for the NUWC measurement program. Four other projects also established tracking efforts. The approach will be built into NUWC's current software change proposal (SCP) system as part of its product line operations.

This report summarizes the steps NUWC has taken to establish a measurement program. NUWC created a software measurement team consisting of representatives from projects participating in the product line effort. That team established goals that the product line effort should attain and formalized questions to ask about the effort to track progress toward those goals. The team also identified indicators that graphically illustrate progress and the data elements needed to produce them. The report concludes with a summary of the results to date and a list of the next steps to be taken to refine the measurement program. 


\section{Abstract}

The Naval Undersea Warfare Center (NUWC) Division Newport Ranges, Engineering, and Analysis Department applied product line practices in the development of systems for the U.S. Navy test ranges it supports. To gauge the success of its product line effort, NUWC must be able to measure the effectiveness of the product line approach compared to more traditional development approaches. To do this, NUWC established a software measurement team to develop and monitor a measurement program. The team includes representatives from programs using the NUWC core asset base, RangeWare. Four projects are currently contributing to the measurement program. This report documents NUWC's approach for measurement by describing the Goal-Driven Software Measurement approach adopted by the test range product line effort and by providing early results of the measurement program. 


\section{Introduction}

The Naval Undersea Warfare Center (NUWC) ${ }^{1}$ Division Newport Ranges, Engineering, and Analysis Department instituted a measurement program to track progress within its software product line activity. The RangeWare core asset base developed at NUWC represents the foundation of the software product line for U.S. Navy range systems [Cohen 02]. The product line includes approximately seven systems already installed, with five to six new projects per year that support range systems for the Navy. The measurement program, once fully institutionalized, will look at the entire product line production process [Clements 02], including core asset development, product development, and management activities. This report describes the steps NUWC took to develop the measurement program and to establish a measurement team with representatives from the various product line projects.

The systems in NUWC's product line support test and evaluation (T\&E) and training ranges, encompass a number of mission areas including live open air ranges, hardware-in-the-loop simulations, and other specialized simulations. Software capabilities supported by the RangeWare core asset base include resources for major range subsystems such as sensors, simulators/stimulators, radar devices, analyzers, and other equipment. A Department of Defense (DoD) test or training exercise will integrate a mix of these resources with actual weapon systems and their operators. A typical exercise may include firing a test torpedo at a drone undersea vehicle and tracking the torpedo through the use of an in-water hydrophone array. Cohen, Dunn, and Soule provide a full description of the core asset base and the process NUWC used to build the core asset base, field initial products, and establish management controls [Cohen 02].

\subsection{Measurement Programs}

A measurement program identifies and defines software measures to support an organization's business goals [Park 96]. These measures provide insights into the management issues that the organization considers most critical to its success. In establishing a measurement program, the organization selects measures traceable to its business goals. This "goal-driven" approach assures management that data collection activities stay focused on the organization's objectives.

1 NUWC is the U.S. Navy's full spectrum research, development, test, evaluation, engineering, and fleet support center for submarines, autonomous underwater systems, and offensive and defensive weapon systems associated with undersea warfare. The team participating in this case study is from the Ranges, Engineering, and Analysis Department at Division Newport and focuses on the design, development, deployment, and maintenance of undersea range systems. References to NUWC in this case study refer to this specific team, not the entire organization. 
In goal-driven measurement, the primary question is not "What metrics should I use?" but rather "What do I want to know or learn?” [Rombach 89]. Because the answers depend on the organization's goals, no fixed set of measures is universally appropriate. Instead of attempting to develop generic, all-purpose lists of questionably useful measures, teams and individuals identify and define measures that provide insights into their own management issues. The process shown in Figure 1 helps an organization identify the data it needs to track to answer the primary question. Steps 1-4 of the process direct the organization to identify its business goals. Steps 5, 6, and 8 produce measurement goals that are necessary to identify what information is most useful to managers (indicators) and to determine success in meeting the business goals. In Steps 7 and 9, the organization identifies the data elements (measures) it must collect, how/when to collect them, and how to report them. A measurement planning step (Step 10) guides the creation of a written plan that the organization and projects will use to set up the measurement program. Details pertaining to each step will be given in subsequent sections of this report.

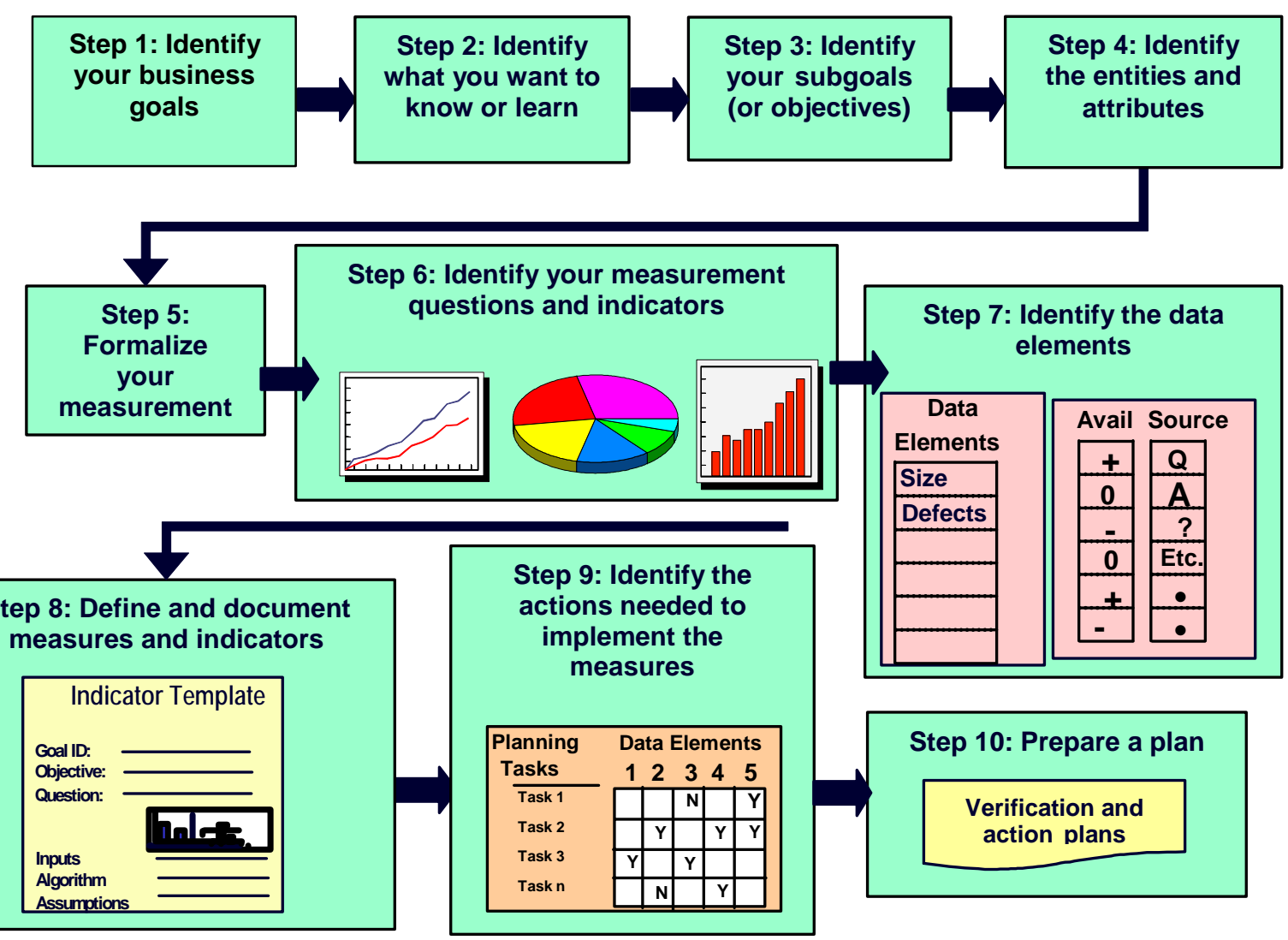

Figure 1: Goal-Driven Software Measurement

\subsection{The NUWC Product Line Activity}

NUWC has an established product line effort and has moved through identifiable phases in its development and use of RangeWare core assets to field range systems [Cohen 99]. The 
core asset development activity involved the creation of the initial core asset base and its use in the development of a small number of products. After the pilot applications of RangeWare, NUWC used the architecture and components to develop new product line systems, improve the core assets, and refine processes such as configuration management for core asset and product development. The concentration on core asset sustainment and product development characterizes a second phase in product line institutionalization. With new projects currently underway, NUWC will expand the coverage of the core asset base and institutionalize practices from the Framework for Software Product Line Practice ${ }^{\mathrm{SM}}$ developed by the Carnegie Mellon ${ }^{\circledR}$ Software Engineering Institute (SEI) [Clements 04]. NUWC is also looking for the most effective and efficient ways to support its customers as it acquires systems from NUWC's development group.

The rest of this report examines NUWC's application of the "Data Collection, Metrics, and Tracking” practice area from the Framework for Software Product Line Practice. To put their measurement program in place, NUWC representatives participated in a Goal-Driven Measurement Workshop. During that workshop, they developed a preliminary description of goals, subgoals, and information requirements. With assistance from the SEI, NUWC refined these preliminary results into a single business goal statement, developed formalized subgoals, and identified indicators. NUWC also established a measurement group with representatives from four range system projects. As of the publication date of this report, four projects have embraced the measurement program and are collecting data and reporting results.

\subsection{Report Organization and Related Work}

Section 2 of this report describes the formation of the product line measurement group and the projects that are currently participating in the measurement program. It also describes how the measurement group applied the 10 steps of the Goal-Driven Measurement process in the following terms:

- establishing business goals and developing questions for the measurement program

- identifying those indicators that the measurement program will provide to managers to help them gauge the effectiveness of the product line approach

- identifying the data elements and sources of information to produce the indicators

Section 3 of this report includes the early results of the NUWC measurement program. Section 4 lists the next steps to improving the overall measurement process.

While this report deals with a measurement program at a single organization, a companion report titled Measures for Software Product Lines discusses, in general, the measurements

${ }^{\text {SM }}$ Framework for Software Product Line Practice is a service mark of Carnegie Mellon University.

${ }^{\circledR}$ Carnegie Mellon is registered in the U.S. Trademark and Patent Office by Carnegie Mellon University.

CMU/SEI-2004-TN-023 
that a product line organization is likely to collect and use [Zubrow 03]. That report presents indicators and measures in terms of product line objectives (performance, compliance, and effectiveness) for management roles within the product line. An organization, such as NUWC, would select those indicators and measures that allow it to gauge the level at which it is meeting its business goals or product line objectives. 


\section{The Software Measurement Program at NUWC}

In establishing its measurement program, NUWC pursued an Initiation Phase followed by a Performance Phase [Clements 04]. In the Initiation Phase, NUWC did the following:

1. Designated the organizational goals to be tracked

2. Defined the indicators (metrics) to be used to track the progress toward NUWC's goals

3. Identified the data to collect to satisfy the indicators

4. Identified the actions needed to implement the measurement program including how and when to collect the data and who will collect the data and report the results

5. Prepared a plan for the measurement program

As of the publication date of this report, NUWC was just beginning the Performance Phase of its measurement program. In carrying out the plan for the program, NUWC will pursue the following steps:

1. Collect the specified data.

2. Analyze the collected data and translate it into the indicators.

3. Determine the management or engineering actions needed to remedy any discovered issues.

4. Verify whether those actions were appropriate for addressing those issues.

The reminder of this section describes the approach NUWC took in establishing its measurement program.

\subsection{Software Measurement Team}

Cohen, Dunn, and Soule describe the early stages in NUWC's institutionalization of its range systems product line [Cohen 02]. The organization successfully fielded a small number of systems to its customers. It collected some rough measures of the products it delivered (including the size of the applications) and used that data to form a high-level business case. The business case showed that the use of RangeWare in fielding range systems could reduce the overall costs by $30 \%$ or more. However, the data used to make the case was collected largely after the fact and could only validate the intuitive notion that product line development lowers development costs. The lower development costs were in the form of cost avoidance when compared to more traditional methods. The reduction in those costs did not result in a refund to any single sponsor, but rather in an ability to get work done under tighter budget constraints. 
To obtain more precise data that justifies the continued refinement of the product line approach, NUWC instituted a measurement program. Under sponsorship of the SEI's Acquisition Support and Product Line Systems Programs, the SEI delivered training and support in goal-driven measurement. NUWC identified four projects as the initial set of participants in its measurement program:

1. Offboard Advanced Systems Stimulus (OASYS)

(Two separate development efforts have stemmed from this project.)

2. RangeWare Improvement (RWI)

(a project separate from the RangeWare core asset base)

3. Fixed Naval Gunfire Support System (FNGSS)

4. Atlantic Underwater Test and Evaluation Center (AUTEC) Shallow Water Mine Range (ASWMR)

The measurement team also used data from a project nearing completion, the East Coast Shallow Water Test Range, as an example of the types of data to collect. Each project listed the above plans to use the RangeWare core assets. They may also use other legacy core assets supported by NUWC.

NUWC established a measurement team with representation from each of these projects. The team has reviewed the business goals, indicators, and data collection requirements to assess their compatibility with individual project goals. Members of the team are also looking at tool support for the measurement program. NUWC currently uses TRACKWeb for the configuration management and bug tracking of RangeWare and other core asset bases. Projects under development or maintenance also use TRACKWeb. In the future, this tool may support data collection for the measurement program.

\subsection{Goals and Questions for a Measurement Program}

NUWC followed Steps 1-4 in the Goal-Driven Measurement process to establish goals and questions for the measurement program. Corporately, NUWC's goal is "working together to deliver the best solutions - quickly." In this context, "working together" means working with the fleet, industry, government laboratories, and academia to harness the solution with the best value for the Navy. The measurement team members felt the primary business goal for the range software product line was to support their corporate charter in their business area. To do so, they would maintain a leadership role in the development of software systems for (primarily undersea) ranges and related range systems. Their charter articulated this goal as follows:

Overall business goal: "Deliver the best-value, high-quality range software systems for our customers-quickly.” 
A key step in meeting this goal is to accurately predict the cost and schedule of projects that deliver these systems. Given the use of RangeWare, NUWC hopes to achieve very high reliability in making these predictions. For these reasons, the measurement team set the following subgoal:

Business subgoal 1: "Improve the accuracy of the cost estimation process."

A second subgoal addresses the issue of product line effectiveness:

Business subgoal 2: "Measure the effectiveness of the product line approach in terms of cost savings over the non-product-line approach.”

To be viewed as a provider of the "best-value" solutions and as an "honest broker" among industry, laboratory, and academic suppliers, NUWC must meet or exceed the expectations of range customers. The "honest broker" role of a government laboratory is distinctly different from private industry. NUWC must offer/integrate the best-value solutions to customer requirements as opposed to selling a solution that will create the most profit. This led to the third subgoal:

Business Subgoal 3: "Ensure that all products meet customers’ requirements and expectations.”

This subgoal acknowledges that additional effort is required in documenting and communicating requirements and expectations. This requires a close working relationship with both customers and sponsors to understand the customers' needs, the operating environment, and the sponsors' resources. The extra effort ensures that the requirements are being met and the developers are not merely responding to perceived shortfalls in a system (i.e., solutions meet a known requirement versus requirement creep).

Business subgoals should not exist for their own purposes; they should address some real need within the product line approach. NUWC refined each of its subgoals (Steps 3 and 4 of Figure 1) to identify meaningful entities, purposes, perspectives, and environments connected to the subgoal. NUWC considered several kinds of entities in forming subgoals, including products, development artifacts, organizational structures, processes, and activities. To establish a purpose for each subgoal, the motivation for collecting and reporting data had to be identified. The perspective identified the stakeholders who were interested in the measurement results. The principal viewpoint was that of manager for the initial goal. The customer will also be a recipient of results. The environment provides a context (processes, tools, and organization) for collecting and interpreting measurement results.

For subgoal 1 (improving the accuracy of cost estimation), the object of interest was the effort estimation process. While the purpose of that subgoal is clearly to improve estimation, it also involves ordering and structuring work tasks from various sources (see Section 2.3) in 
sizes that are measurable and trackable. NUWC has set this subgoal to better understand the causes behind deviations from estimates and to relate those estimates to specific

characteristics of the task or a class of tasks. Finally, NUWC determined that using tools can support the tracking activity, and subgoal 1 can improve how existing tools are used or help determine where new tools are required.

Given this understanding of the measurement, NUWC began to ask specific questions about its product line development process to help achieve its stated goal. Without this refinement, only vaguely stated questions could be addressed, and they shed little light on the measures needed to understand the fundamental attributes of the processes and products that are part of the product line approach. Figure 2 provides a summary of the refinement process for subgoal 1 that leads to specific questions that must be answered by the measurement program.

\begin{tabular}{|ll|}
$\begin{array}{l}\text { Object of Interest } \\
\text { Purpose }\end{array}$ & $\begin{array}{l}\text { Effort estimation } \\
\text { Improve the ability to make reliable estimates of effort. } \\
\text { Perspective }\end{array}$ \\
$\begin{array}{l}\text { Environment and } \\
\text { Constraints }\end{array}$ & $\begin{array}{l}\text { Use TRACKWeb to estimate, track, and report effort } \\
\text { within a project and for comparison across projects. } \\
\text { Interface with additional tools may be required. }\end{array}$ \\
\hline
\end{tabular}

Figure 2: Refinement of Overarching Goal into Subgoal 1

\subsection{Questions and Indicators}

To identify the information most useful to managers, NUWC developed a set of indicators following Steps 5, 6, and 8 in Goal-Driven Software Measurement. As of the publication date of this report, NUWC is using the measurement program to address subgoal 1 (i.e., improve the accuracy of the cost estimation process) in two ways:

1. tracking predictions within a project - that is, how well did the project meet its estimates?

2. tracking predictions across projects - that is, how and why do projects differ in their abilities to make reliable estimates?

This section identifies two things: (1) the questions NUWC asked developers in order to find out how they measured their progress toward subgoal 1 and (2) the results NUWC hopes to attain. 
Each project was broken up into a series of tasks. NUWC defined tasks in three ways: (1) in the project work breakdown structure (WBS), (2) through action items (AIs), and (3) through software change proposals (SCPs). The WBS, AIs, and SCPs had different origins:

- The WBS was generated by NUWC using customer requirements for a given project.

- The AIs that resulted in the generation of software tasks during project reviews or meetings could have originated from multiple sources (customers, sponsors, the engineering team, etc.), but each AI had to be considered trackable by the project.

- Regarding SCPs submitted by a user or developer and entered into TRACKWeb to track and report on their progress, NUWC's configuration control board decided which ones were addressed before they became tasks. That board includes customer representatives.

In addition, tasks differed widely in size based on the nature of the task and how the project developed its WBS. The scope of most tasks was known when defined, but others had significant unknowns or included multiple subtasks. Although the WBS lists individual tasks, the level of detail for software-specific tasks varied greatly from project to project. In some cases, software development appeared as only a single line in the project-level WBSs for multidisciplinary projects. The software developers had to break the WBS line item down to a level that could be adequately tracked and then estimated the effort required to complete that task. Tasks were sometimes further divided into subtasks to obtain a maximum of a twoweek level of effort for an individual task. NUWC asked the following questions about these tasks:

- How accurately do we estimate the effort to complete them?

- How does the accuracy of estimates compare across tasks in a single project?

- How does the accuracy compare across multiple projects?

- Will effort estimates be of comparable quality (i.e., are all projects equally good in making estimates)?

- How will estimates vary based on projects of different size? different levels of reuse?

- Will the reliability of estimates vary depending on the source of the task: WBS, AI, and SCP work?

By measuring variance in terms of cost, effort, and schedule, NUWC hoped to identify deviations and their causes. The measurement program fed results back to projects to improve the reliability of future estimates.

For this element of the measurement program, NUWC represented the results in a series of bar charts. Figure 3 shows the indicator for effort variance. NUWC generated additional charts for cost and schedule variance. Within the effort variance indicator and for each project, task variance was either positive (if the actual effort exceeded the estimate) or negative (if the task was completed in less time then estimated). Tasks were sometimes grouped by source (WBS, AI, SCP) to address question 6 above. NUWC plans to develop an 
aggregate variance for a project and then use an indicator to compare variance across projects to address questions 3-5. NUWC is still developing a method for aggregating data and comparing data across projects. In addition to the individual variance indicators, NUWC plans to develop an indicator that shows all three variances: effort, cost, and schedule.

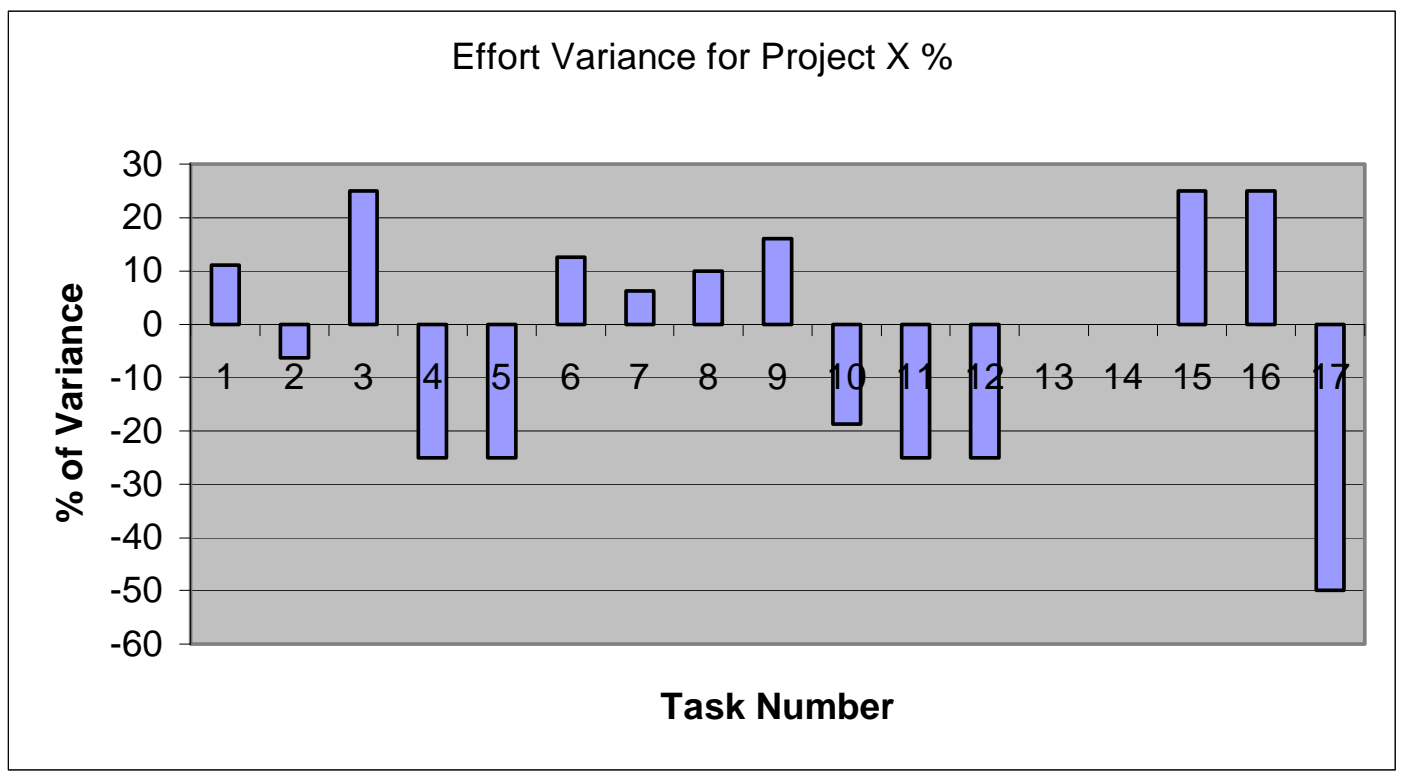

Figure 3: Effort Indicator for Improving the Accuracy of Cost Estimation

\subsection{Data Elements and Sources}

NUWC determined the specific data needs required to answer the questions and build the indicators for each subgoal. Focusing on specific data needs, NUWC collected only the data actually needed. NUWC connected each data element to a specific indicator or to multiple indicators if it could serve multiple needs.

Table 1 illustrates the relationship between the collected data elements and the indicators for subgoal 1 . The priorities for this subgoal are data elements 8-14, which contain both estimated and actual effort, schedule, and cost data. 
Table 1: Data Elements that Are Collected for Subgoal 1

\begin{tabular}{|l|c|c|c|}
\cline { 2 - 4 } \multicolumn{1}{c|}{} & \multicolumn{3}{c|}{ Indicator } \\
\hline Data Elements Required & $\begin{array}{c}\text { Effort } \\
\text { Variance }\end{array}$ & $\begin{array}{c}\text { Schedule } \\
\text { Variance }\end{array}$ & $\begin{array}{c}\text { Cost } \\
\text { Variance }\end{array}$ \\
\hline 1 Identifier & $X$ & $X$ & $X$ \\
\hline 2 Description & $X$ & $X$ & $X$ \\
\hline 3 Requirement & $X$ & $X$ & \\
\hline 4 Baseline (Effort, Completion) & $X$ & $X$ & \\
\hline 5 Revised Baseline & $X$ & $X$ & \\
\hline 6 Number of Revision (History) & $X$ & $X$ & \\
\hline 7 Rationale for Revision & $X$ & $X$ & \\
\hline 8 Actual Effort to Date & $X$ & $X$ & \\
\hline 9 Estimate Effort to Complete & & $X$ & \\
\hline 10 Estimate Actual Completion Date & & & \\
\hline 11 Revised Completion Date & & & \\
\hline 12 Labor Resource Cost & & & \\
\hline 13 Revised Costs & & & \\
\hline 14 Other Task Cost & & & \\
\hline 15 Actual Figures (Effort, Schedule, \\
Cost) at Completion & & & \\
\hline
\end{tabular}

Table 2 illustrates the relationship between the collected data elements and the indicators for subgoal 1 . 
Table 2: $\quad$ Data Elements that Are Computed for Subgoal 1

\begin{tabular}{|l|c|c|c|}
\cline { 2 - 4 } \multicolumn{2}{c|}{} & \multicolumn{3}{c|}{ Indicator } \\
\hline Data Elements Required & $\begin{array}{c}\text { Effort } \\
\text { Variance }\end{array}$ & $\begin{array}{c}\text { Schedule } \\
\text { Variance }\end{array}$ & $\begin{array}{c}\text { Cost } \\
\text { Variance }\end{array}$ \\
\hline Compute & & $X$ & $X$ \\
\hline Baseline Cost (Labor and Other) & & $X$ & $X$ \\
\hline Costs to Date & $X$ & $X$ & $X$ \\
\hline$\%$ Completed (Schedule, Effort) & $X$ & & $X$ \\
\hline$\%$ Actual Effort Spent & $X$ & $X$ & \\
\hline $\begin{array}{l}\text { Estimate (Effort, Cost) at } \\
\text { Completion }\end{array}$ & & & \\
\hline Variance (Effort, Schedule, Cost) & & & \\
\hline
\end{tabular}

The identification of a small number of required data elements allays a critical concern in the data collection process. Given the number of data elements required, managers and engineers would be concerned with the time and dedication needed to accurately track information for the indicators. NUWC has selected 15 data elements. Some, such as 1-3, characterize the data elements. Others, such as 4-7, represent estimates of cost or effort that will be gathered at the start of a task or project. After analysis, NUWC found that only one element-Actual Effort to Date-would need to be collected on an ongoing basis. The remainder of the data elements would need to be gathered only once or, at worst, infrequently when a date or estimate changed. Other measures required for the indicators (listed in Table 2) can be computed for the data elements themselves and therefore do not impose any collection effort on the engineers.

While ongoing data collection requirements were minimal, many data elements were not immediately available at the initiation of the measurement program. In fact, the only information consistently tracked about a task is its name, description, and baseline effort. Baseline effort might be updated over the course of a task's execution or as a result of an activity associated with another task, but a history of these changes isn't necessarily maintained. The rationale for the change might or might not be recorded. NUWC studied the data requirements to assess their availability and the effort required to consistently track a specific data element. With only one exception, all data could be obtained with minimal additional effort. The chart also shows a one-to-many mapping for most of the data elements: one data element supports the creation of multiple indicators.

Data elements, collected under Step 7 of Figure 1, come from a variety of sources. Project documents such as the WBS or requirements documents are a source of information about 
several of the data elements. Project team members are responsible for other data; they must create and record estimates, make revisions to those estimates, provide a rationale for changes, and report the actual work accomplished. NUWC does not currently collect much of this data at the level of granularity required to meet the organization's new measurement goals. The project personnel must be taught how to collect, record, and report data elements. Table 3 shows the availability of each required data element before initiation of the measurement program. The legend indicates the meaning of the symbols for availability status. While none of the required data items were very hard to capture, NUWC recognized the effort required to begin collecting data, essentially for the first time. The third column in Table 3 shows the source identified for providing information for each data element.

Armed with the complete list of required data elements, their sources, and their applicability to specific indicators, NUWC created a data collection and reporting procedure. The next section shows the initial results of applying the procedure to a single project.

Table 3: Availability and Sources of Required Data Elements

\begin{tabular}{|l|c|l|}
\hline Data Elements Required & Availability & Source \\
\hline 1 Identifier & + & WBS, SCP, Al \\
\hline 2 Description & + & WBS, SCP, Al \\
\hline 3 Requirement & 000 & Requirements document \\
\hline 4 Baseline (Effort, Completion) & + & WBS (sometimes), AI \\
\hline 5 Revised Baseline & 00 & Staff \\
\hline 6 Number of Revision (History) & 00 & Staff (not collected now) \\
\hline 7 Rationale for Revision & 00 & Staff (not collected now) \\
\hline 8 Actual Effort to Date & 00 & Timesheets, staff \\
\hline 9 Estimate Effort to Complete & 00 & Staff \\
\hline $\begin{array}{l}10 \text { Estimate Actual Completion } \\
\text { Date }\end{array}$ & 00 & Staff \\
\hline 11 Revised Completion Date & 00 & Staff \\
\hline 12 Labor Resource Cost & 00 & Staff \\
\hline 13 Revised Costs & 00 & Staff \\
\hline 14 Other Task Cost & 00 & Staff \\
\hline $\begin{array}{l}\text { 15 Actual Figures (Effort, } \\
\text { Schedule, Cost) at Completion }\end{array}$ & 00 & Staff \\
\hline $\begin{array}{l}\text { Baseline Cost (Labor and } \\
\text { Other) }\end{array}$ & 0 & Baseline effort * labor cost \\
\hline Costs to Date & 0 & Actual effort * labor cost \\
\hline
\end{tabular}


Table 3: $\quad$ Availability and Sources of Required Data Elements (continued)

\begin{tabular}{|l|c|l|}
\hline Data Elements Required & Availability & Source \\
\hline $\begin{array}{l}\text { \% Completed (Schedule, } \\
\text { Effort) }\end{array}$ & 0 & Actual/baseline $\star 100$ \\
\hline$\%$ Actual Effort Spent & 0 & Actual/to complete $\star 100$ \\
\hline $\begin{array}{l}\text { Estimate (Effort, Cost) at } \\
\text { Completion }\end{array}$ & 0 & To complete - actual \\
\hline $\begin{array}{l}\text { Variance (Effort, Schedule, } \\
\text { Cost) }\end{array}$ & 0 & To complete/baseline $\star 100$ \\
\hline
\end{tabular}




\section{Results}

NUWC collected data for one project and provided the actual effort results to test the assumptions of the measurement program. Table 4 shows the results of the "straw man" application of the measurement process on the East Coast Shallow Water Test Range (ECSWTR). The data in this chart showed several areas, described below, that needed to be improved for more effective collection and reporting.

Tasks report a baseline across several orders of magnitude. The "Printing display of range data” and "XyView doesn't support Lat/Lon" (to add latitude/longitude to the display) tasks are full development efforts for the subsystem. These tasks fall far outside the two-week task boundary. Other tasks are small, one- or two-day efforts.

- The large number of small tasks impedes variance comparison. A few extra hours on a small task causes a severe rise in variance. A shift of a few hours on a large task is barely noticeable. Separate baselines for comparison can be established for large and small tasks. For large ones, a percentage basis is a reasonable baseline; for small tasks, a certain number of hours is.

- it would be reasonable to establish the baseline in terms of hours.

- Although NUWC encountered no resistance to collecting data, data collection has not become a routine part of the development process. Managers must often make estimates to fill in gaps where developers did not report the actual results, and, for other tasks, the effort was completed before actual effort reporting began.

- Estimates are currently imprecise. NUWC does not have a process in place to account for causes of variance. Clearly, for variance above a certain threshold, the factors contributing to the inaccuracy of the estimate should be noted. Among those factors suggested are

- adding new requirements to a task without adjusting the effort estimate

- attributing time to a single task when work was performed on other tasks as well

- determining where to account for effort not directed to a specific task

These results were used to improve collection on the four projects that are now launching the measurement effort. 
Table 4: Initial Results from Data Collection

\begin{tabular}{|c|c|c|c|c|}
\hline Task or Software Change Request & \begin{tabular}{|c|} 
Baseline \\
Effort
\end{tabular} & $\begin{array}{c}\text { Actual } \\
\text { Effort (est.) }\end{array}$ & \begin{tabular}{c|} 
Effort \\
Variance $\%$
\end{tabular} & Notes \\
\hline ECSWTR audio mixing & - & & & Completed \\
\hline ECSWTR can't handle multiple streams of audio. & - & & & Completed \\
\hline Network audio tool can hang RangeWare. & - & & & Completed \\
\hline Hydrophones are miscolored wrt to operations. & - & & & Completed \\
\hline ECSWTR UCS documentation & 0.0 & 48.0 & & Not in original estimate \\
\hline graphical user interface for node operations & 40.0 & 0.0 & & Eliminated \\
\hline Evaluate and close finished software change proposals (SCPs). & 20.0 & 20.0 & $0.00 \%$ & \\
\hline Ant scripts for builds & 20.0 & 40.0 & $100.00 \%$ & \\
\hline StripView objects always have a history. & 26.4 & 34.4 & $30.30 \%$ & Code completed; needs review \\
\hline XyView has trouble clearing its history. & 26.4 & 26.4 & $0.00 \%$ & \\
\hline XyView history doesn't handle 0 history points. & 27.2 & 27.2 & $0.00 \%$ & \\
\hline StripView always looks like it receives data. & 20.0 & 116.0 & $480.00 \%$ & Code completed; needs review \\
\hline XyView scaling grid dialog needs improvement. & 8.0 & 8.0 & $0.00 \%$ & \\
\hline XyView doesn't support Lat/Lon. & 105.0 & 105.0 & $0.00 \%$ & Lat/Long grid on $X Y$ display \\
\hline XyView ignores assets that don't update XY. & 5.6 & 8.0 & $42.86 \%$ & It is supposed to do that! \\
\hline XyView needs to display units. & 9.6 & 9.6 & $0.00 \%$ & \\
\hline RangePoint doesn't document units. & 8.0 & 8.0 & $0.00 \%$ & \\
\hline LATR/RDA applications don't close window as expected. & 20.0 & 20.0 & $0.00 \%$ & \\
\hline Tsunami starting from RW & 20.0 & 0.0 & $-100.00 \%$ & \\
\hline TextView should use a DA instead of an asset. & 20.0 & 20.0 & $0.00 \%$ & \\
\hline TextView needs a scrollbar. & 40.0 & 40.0 & $0.00 \%$ & \\
\hline TextView needs to display time in a reasonable fashion. & 20.0 & 20.0 & $0.00 \%$ & \\
\hline StripView/XyView needs to display units. & 40.0 & 48.0 & $20.00 \%$ & Code completed; needs review \\
\hline Display classification of exercise & 20.0 & 20.0 & $0.00 \%$ & \\
\hline Printing display of range data & 400.0 & 80.0 & $-80.00 \%$ & BitMap dumps only \\
\hline PrototypeNative Lat/Long View & 0.0 & 10.0 & & Not in original estimate \\
\hline FTL Support & 0.0 & 6.0 & & Not in original estimate \\
\hline
\end{tabular}

As more projects begin to collect and report data, NUWC expects to see improvements in the precision of its estimates. NUWC will also need to develop training for team members who provide estimates or record the actual work performed, so they maintain accurate time reports. NUWC will also make comparisons within and between projects to determine reasons for variance at the project level. 


\section{Next Steps}

NUWC will continue to institutionalize its measurement program. The next steps involve expanding the coverage of measurement in both breadth (number of projects) and depth (addressing all subgoals). NUWC will also look at defining a full production plan. These next steps include the following:

- In this initiation of the measurement program, NUWC has looked at only one subgoal and a few projects. As the measurement program matures, NUWC will complete the characterization of its other two subgoals:

Subgoal 2: "Ensure the effectiveness of the product line approach.” For this subgoal, which establishes the actual value of the product line effort, NUWC will ask questions such as

1. Which core assets are used most often?

2. What is the degree of core asset reuse in a project (i.e., what percentage of a project is derived from the core assets)? NUWC's goal is to maximize the percentage of deployed systems using product line core assets by numbers of requirements, numbers of components, or lines of code.

3. At what cost, schedule, and effort are core assets used?

4. How often are core assets updated?

5. At what cost, schedule, and effort do these updates take place?

6. Are the updates planned in response to bugs the result of redesigning other core assets?

7. Do updates fall into specific categories?

8. How many new core assets are developed?

9. Are projects completed sooner and/or with less effort?

10. Do products have fewer defects?

11. Can products be changed faster when requirements change?

The measurement group has not yet developed the specific indicators that will be used with this goal. However, at least one indicator will show comparisons of the cost of completing a project with core assets (including any allocated asset development costs) and without them. It will also consider applying measures other than those at the code level, that is, looking across the core assets including requirements, architecture, subsystem design, testing, and planning. 
Subgoal 3: "Ensure that all products meet customers' requirements.” To address this subgoal, NUWC must define measures to better understand the value of the project line to its customers and assure management that the product line approach is addressing range customers' and users' needs in terms of requirements traceability and metrics for quality assurance (QA) and testing. A comparison between projects developed using core assets versus projects using other development approaches will require customer feedback measures such as the number of defect reports or the lead time to support range user exercise requirements.

- The NUWC software product line activity remains a largely informal process. Project teams use RangeWare core assets and follow some common processes, but the overall development approach is not captured in a production plan. In the next round of the product line's institutionalization, NUWC plans to look at all of its processes, including core asset creation and sustainment, product development and maintenance, and management processes. The production plan could also examine steps in the Performance Phase of a measurement program for product lines. (See Section 2.) The results of a measurement program will help shape the analysis and development of the more formal process.

- NUWC will institute an analysis program to make comparisons across projects. The analysis will track improvements in overall estimating, reductions in the reuse costs of RangeWare or other core assets, reductions in overall project costs due to the use of core assets, and product effectiveness as reported through customer feedback. Analysis will also play a role in NUWC's long-term strategies for tasks such as documenting the business case for new investment in the product line and supporting a decision process for tradeoffs between specific improvements. For example, budget limitations may make it impossible to address all SCPs. The analysis will provide a more formal means to make judgments concerning which proposals should be approved. 


\section{References}

URLs are valid as of the publication date of this document.

[Clements 02] Clements, Paul \& Northrop, Linda. Software Product Lines: Practices and Patterns. Boston, MA: Addison-Wesley, 2002.

[Clements 04] Clements, Paul \& Northrop, Linda. A Framework for Software Product Line Practice, Version 4.2. http://www.sei.cmu.edu/plp /framework.html (2004).

[Cohen 99] Cohen, Sholom. Guidelines for Developing a Product Line Concept of Operations (CMU/SEI-99-TR-008, ADA367714). Pittsburgh, PA: Software Engineering Institute, Carnegie Mellon University, 1999. http://www.sei.cmu.edu/publications/documents/99.reports/99tr008 /99tr008abstract.html

[Cohen 02] Cohen, Sholom; Dunn, Ed; \& Soule, Albert. Successful Product Line Development and Sustainment: A DoD Case Study (CMU/SEI-2002-TN018, ADA407788). Pittsburgh, PA: Software Engineering Institute, Carnegie Mellon University, 2002. http://www.sei.cmu.edu/publications /documents/02.reports/02tn018.html

[Park 96] Park, Robert E.; Goethert, Wolfhart B.; \& Florac, William A. GoalDriven Software Measurement-A Guidebook (CMU/SEI-96-HB-002, ADA313946). Pittsburgh, PA: Software Engineering Institute, Carnegie Mellon University, 1996. http://www.sei.cmu.edu/publications /documents/96.reports/96.hb.002.html

[Rombach 89] Rombach, H. Dieter \& Ulery, Bradford T. "Improving Software Maintenance Through Measurement.” Proceedings of the IEEE 77, 4 (April 1989): 581-595.

[Zubrow 03] Zubrow, Dave \& Chastek, Gary. Measures for Software Product Lines (CMU/SEI-2003-TN-031, ADA418393). Pittsburgh, PA: Software Engineering Institute, Carnegie Mellon University, 2003.

http://www.sei.cmu.edu/publications/documents/03.reports/03tn031.html 


\begin{tabular}{|c|c|c|c|c|c|}
\hline \multicolumn{4}{|c|}{ REPORT DOCUMENTATION PAGE } & \multicolumn{2}{|c|}{$\begin{array}{l}\text { Form Approved } \\
\text { OMB No. 0704-0188 }\end{array}$} \\
\hline \multicolumn{6}{|c|}{ 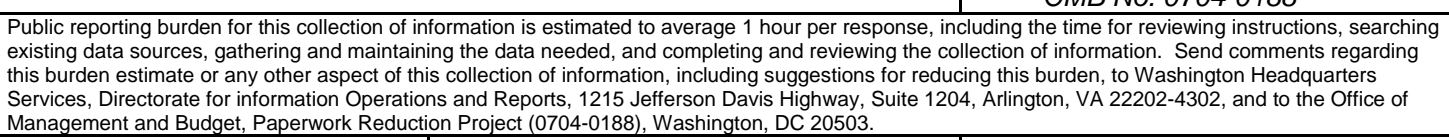 } \\
\hline 1. & $\begin{array}{l}\text { AGENCY USE ONLY } \\
\text { (Leave Blank) }\end{array}$ & \multicolumn{2}{|l|}{$\begin{array}{l}\text { on Project (0704-0188), } \\
\text { 2. } \\
\text { MEPORT DATE } 2004\end{array}$} & \multicolumn{2}{|c|}{$\begin{array}{l}\text { 3. REPORT TYPE AND DATES COVERED } \\
\text { Final }\end{array}$} \\
\hline & \multicolumn{3}{|c|}{$\begin{array}{l}\text { TITLE AND SUBTITLE } \\
\text { Case Study: A Measurement Program for Product Lines }\end{array}$} & \multicolumn{2}{|c|}{$\begin{array}{ll}5 . & \text { FUNDING NUMBERS } \\
& \text { F19628-00-C-0003 }\end{array}$} \\
\hline & \multicolumn{5}{|l|}{$\begin{array}{l}\text { AUTHOR(s) } \\
\text { Sholom Cohen, D }\end{array}$} \\
\hline & \multicolumn{3}{|c|}{$\begin{array}{l}\text { PERFORMING ORGANIZATION NAME(S) AND ADDRESS(ES) } \\
\text { Software Engineering Institute } \\
\text { Carnegie Mellon University } \\
\text { Pittsburgh, PA } 15213\end{array}$} & \multicolumn{2}{|c|}{$\begin{array}{ll}\text { 8. } & \text { PERFORMING ORGANIZATION } \\
\text { REPORT NUMBER } \\
\text { CMU/SEI-2004-TN-023 }\end{array}$} \\
\hline & \multicolumn{3}{|c|}{$\begin{array}{l}\text { SPONSORING/MONITORING AGENCY NAME(S) AND ADDRESS(ES) } \\
\text { HQ ESC/XPK } \\
5 \text { Eglin Street } \\
\text { Hanscom AFB, MA 01731-2116 }\end{array}$} & \multicolumn{2}{|c|}{$\begin{array}{l}\text { 10. SPONSORING/MONITORING AGENCY } \\
\text { REPORT NUMBER }\end{array}$} \\
\hline \multicolumn{6}{|c|}{ 11. SUPPLEMENTARY NOTES } \\
\hline \multicolumn{4}{|c|}{$\begin{array}{l}\text { 12A DISTRIBUTION/AVALABBILTY STATEMENT } \\
\text { Unclassified/Unlimited, DTIC, NTIS }\end{array}$} & \multicolumn{2}{|c|}{ 12B DISTRIBUTION CODE } \\
\hline & \multicolumn{5}{|c|}{$\begin{array}{l}\text { The Naval Undersea Warfare Center (NUWC) Division Newport Ranges, Engineering, and Analysis } \\
\text { Department applied product line practices in the development of systems for the Navy test ranges it supports. } \\
\text { To gauge the success of its product line effort, NUWC must be able to measure the effectiveness of the } \\
\text { product line approach compared to more traditional development approaches. To do this, NUWC established } \\
\text { a software measurement team to develop and monitor a measurement program. The team includes } \\
\text { representatives from programs using the NUWC core asset base, RangeWare. Four projects are currently } \\
\text { contributing to the measurement program. This report documents NUWC's approach for measurement by } \\
\text { describing the Goal-Driven Software Measurement approach adopted by the test range product line effort and } \\
\text { by providing early results of the measurement program. }\end{array}$} \\
\hline & \multicolumn{3}{|c|}{$\begin{array}{l}\text { SUBJECT TERMS } \\
\text { software measurement, software product lines, software metrics, } \\
\text { product line case study }\end{array}$} & \multicolumn{2}{|c|}{$\begin{array}{l}\text { 15. NUMBER OF PAGES } \\
32\end{array}$} \\
\hline \multicolumn{6}{|c|}{ 16. PRICE CODE } \\
\hline & $\begin{array}{l}\text { SECURITY CLASSIFICATION } \\
\text { OF REPORT } \\
\text { Unclassified }\end{array}$ & $\begin{array}{l}\text { 18. SECURITY CLASSIFICATION OF } \\
\text { THIS PAGE } \\
\text { Unclassified }\end{array}$ & $\begin{array}{l}\text { 19. SECURITY CLAS } \\
\text { ABSTRACT } \\
\text { Unclassifie }\end{array}$ & SIFICATION OF & $\begin{array}{l}\text { 20. LIMITATION OF ABSTRACT } \\
\text { UL }\end{array}$ \\
\hline
\end{tabular}

